\title{
A PROSPECTIVE STUDY ON MANAGEMENT OF POST BURN CONTRACTURE WITH SPECIAL REFERENCE TO SCAR SCORING AND REHABILITATION
}

\author{
Varsha Dhakad', Sonia Moses², Sachin Verma33, Abhishek Kumar Verma ${ }^{4}$ \\ ${ }_{1}^{1}$ Associate Professor, Department of Surgery, MGM Medical College and M. Y. Hospital, Indore, Madhya Pradesh, India. \\ ${ }^{2}$ Associate Professor, Department of Surgery, MGM Medical College and M. Y. Hospital, Indore, Madhya Pradesh, India. \\ ${ }^{3}$ Associate Professor, Department of Surgery, MGM Medical College and M. Y. Hospital, Indore, Madhya Pradesh, India. \\ ${ }_{4}^{4}$ Resident, Department of Surgery, MGM Medical College and M. Y. Hospital, Indore, Madhya Pradesh, India.
}

\section{ABSTRACT}

\section{BACKGROUND}

Post burn contractures cause varying degree of functional and cosmetic problems and have tendency to recur even after intervention. Operative correction is usually recommended to release scar, restore function and improve cosmesis as these contractures do not heal on their own and even after intervention, they have a tendency to recur. Thus, additional interventions like splints and physiotherapy may be employed to minimize recurrence. The primary objective of this study was to evaluate the contracture scars based on a quantitative scale, their treatment modalities and patient compliance with rehabilitation protocol by assessing them at follow up visits over a course of six months.

\section{MATERIALS AND METHODS}

This was an observational study involving patients of all age groups and both sexes seeking treatment for post burn contractures for the first time at a tertiary care hospital. The scars were evaluated as per Clinical Assessment Score and functional status assessed by measuring deficit in patients' range of motion as compared to normal, at presentation, immediate postoperative period and at the end of six months follow-up.

\section{RESULTS}

Fifty patients were included. At presentation, Mean Clinical Assessment Score was 13.75 which reduced to 10.47 at follow up while Mean Deficit in Range of Motion reduced from $75.30 \%$ at presentation to $27.27 \%$ at the end of six months. $74 \%$ had achieved nearnormal functionality by surgery while others reached acceptable level. $20 \%$ were lost to follow up. Clinical Assessment Score and Functional status worsened over six months of follow up. $83 \%$ of patients using splints had deficit less than $25 \%$ at the end of six months while $90 \%$ of those not using splints had deficit between $26 \%$ to $50 \%$. 55\% of patients treated with flaps had less than $25 \%$ deficit while $45 \%$ patients treated with grafts achieved this level at six months. $46 \%$ of patients treated with flap had scar scoring 9 or less while $21 \%$ of those treated with grafting could achieve the same at six months.

\section{CONCLUSION}

In our study, most patients of post burn contracture presented with severe scarring and functional restriction. A good level of correction could be achieved surgically but worsening of scar and functionality was observed over six months, although using splints could prevent it to some extent. Flap surgeries showed better outcome than grafting. Surgeries employing flap are recommended wherever possible for the treatment and proper adherence to rehabilitation protocol is important in the outcome.

\section{KEY WORDS}

Post Burn Contractures, Clinical Assessment Score.

HOW TO CITE THIS ARTICLE: Dhakad V, Moses S, Verma S, et al. A prospective study on management of post burn contracture with special reference to scar scoring and rehabilitation. J. Evolution Med. Dent. Sci. 2019;8(05):321-325, DOI: 10.14260/jemds/2019/69

\section{BACKGROUND}

In India, over 10,00,000 people are moderately or severely burnt every year.[1] As the mortality from burns have decreased, their long term sequel like contractures and related morbidity have increased in recent times as more severely burned patients are surviving. These contractures cause major functional and cosmetic problems and have adverse economic, social and psychological implications.

'Financial or Other Competing Interest': None.

Submission 03-10-2017, Peer Review 19-01-2019,

Acceptance 28-01-2019, Published 04-02-2019.

Corresponding Author:

Abhishek Kumar Verma,

Department of Surgery,

Ground Floor, Old Building,

Maharaja Yashwantrao Hospital,

Indore-452001, Madhya Pradesh, India.

E-mail: abhishekkumarverma@gmail.com

DOI: $10.14260 /$ jemds $/ 2019 / 69$

\section{(c) $(1)$}

Moreover, they may also cause debilitating levels of chronic pain. Thus even after surviving burns, the victim may not be able to lead a normal life.[2,3] Operative correction is usually recommended to release scar, restore function and improve cosmoses as these contractures do not heal on their own and even after intervention they have tendency to recur. Thus additional intervention like splints and physiotherapy may be employed to prevent recurrence.[4-7] This study was done to assess types of contractures that patients present with at MY Hospital, Indore; to describe various treatment modalities that are employed to correct deformities and evaluate the outcomes with respect to improvement in functionality and scar scoring and thus restore the patient's condition to pre-injury status. This study evaluated the contractures based on a quantitative scale thus providing a data on nature of contractures that patients present with. Since long term use of splints, physiotherapy, etc. are an essential part of treatment beside operative procedures, the study was needed to evaluate the patient compliance with 
rehabilitation protocol by assessing them at follow up visits over a course of six months. Scientific data highlighting characteristics of presenting scars and their management will help in framing better management protocols which will help in decreasing morbidity related to burn contractures Furthermore this study highlights the importance of patient compliance with rehabilitation protocols to prevent recurrence and improve functional outcomes after surgery.

\section{MATERIALS AND METHODS}

This was an observational study. Patients of all age groups and both sexes treated in M.Y. Hospital, Indore from January 2016 to August 2017 were included. A total of 50 contractures were studied. Evaluation began with scar scoring as per Clinical Assessment Score, measurement of Range of movement. Treatment modality employed surgical intervention in the form of release of contracture followed by grafting, flap or zplasty as deemed suitable in the case. Following surgery, POP slabs and splints were used to maintain the limb in functional position. During follow up visits, note was made of compliance with the rehabilitation protocol (use of splints), any change in range of movement of joints. Range of motion (ROM) of the patient was calculated as percentage of normal ROM and the difference between normal and observed value was calculated as percentage deficit in ROM.

\section{Normal ROM was taken as follows-}

1. Wrist joint (Flexion-Extension): $70^{\circ}$

2. Fingers (Composite ROM of all Joints): $180^{\circ}$

3. Neck (Flexion-Extension): $55^{\circ}$

4. Axilla (Abduction-Adduction): $180^{\circ}$

5. Elbow (Flexion-Extension): 180

In case of recurrence, requirement of second surgery was recorded as outcome during follow up, and then such patients were not followed up after second surgery as they came under exclusion criteria.

\section{Statistical Analysis}

Data was analysed using SPSS Version 16.0. Paired t-test was used to assess statistical significance of the results.

\section{RESULTS}

1. Type of Scar Contracture at Presentation

a) Type of scar contracture with which the patients present as per scar assessment score

\begin{tabular}{|c|c|c|c|}
\hline Scar Assessment Score & $\mathbf{9}$ or Less & $\mathbf{1 0 - 1 3}$ & $\begin{array}{c}\text { More Than } \\
\mathbf{1 3}\end{array}$ \\
\hline No. of Patients & 0 & 27 & 23 \\
\hline Percentage & 0 & $54 \%$ & $46 \%$ \\
\hline \multicolumn{3}{|c|}{ Table 1 } \\
\hline
\end{tabular}

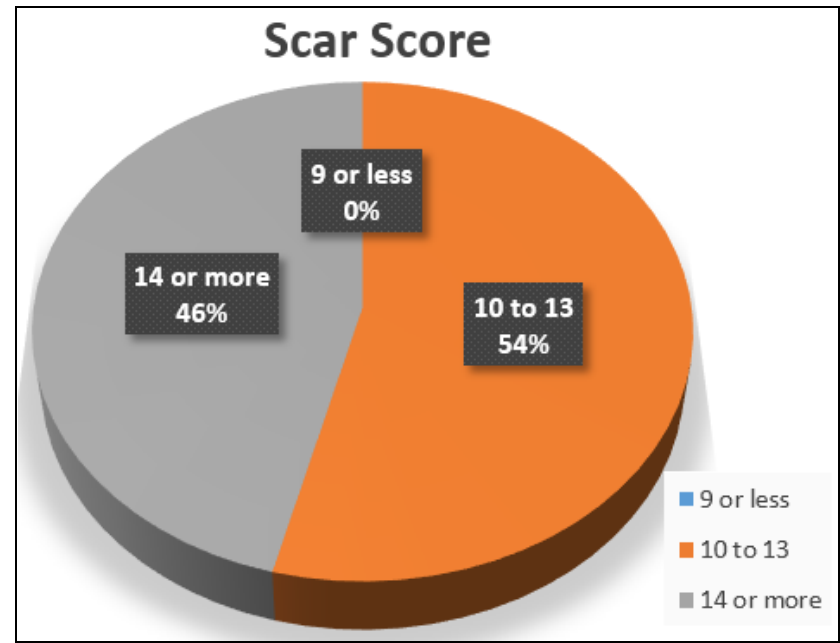

b) Deficit in range of movement (ROM) of joint as percentage of normal ROM at presentation

\begin{tabular}{|c|c|c|c|}
\hline Deficit & $\mathbf{5 0 \%}$ or Less & $\mathbf{5 1 \% - 7 5 \%}$ & $\begin{array}{c}\text { More Than } \\
\mathbf{7 5 \%}\end{array}$ \\
\hline No. of Patients & 6 & 17 & 27 \\
\hline $\begin{array}{c}\text { Percentage of } \\
\text { Patients }\end{array}$ & $12 \%$ & $24 \%$ & $54 \%$ \\
\hline \multicolumn{4}{|c|}{ Table 2 } \\
\hline
\end{tabular}

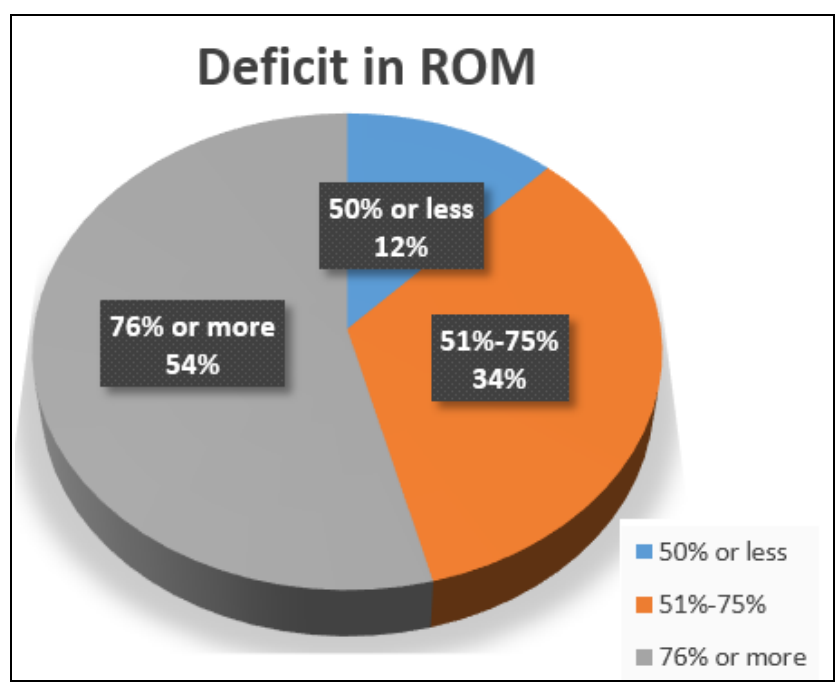

2. Treatment Modality*

\begin{tabular}{|c|c|c|c|}
\hline Surgery & Z-Plasty & $\begin{array}{c}\text { Release \& } \\
\text { Grafting }\end{array}$ & $\begin{array}{c}\text { Release \& } \\
\text { Flap }\end{array}$ \\
\hline No. of Patients & 3 & 39 & 8 \\
\hline Percentage of Patients & $6 \%$ & $78 \%$ & $16 \%$ \\
\hline \multicolumn{3}{|c|}{ Table 3 } \\
\hline $\begin{array}{c}\text { * POP slab was applied to all patients postoperatively and } \\
\text { splint was advised to all patients at discharge }\end{array}$ \\
\hline
\end{tabular}




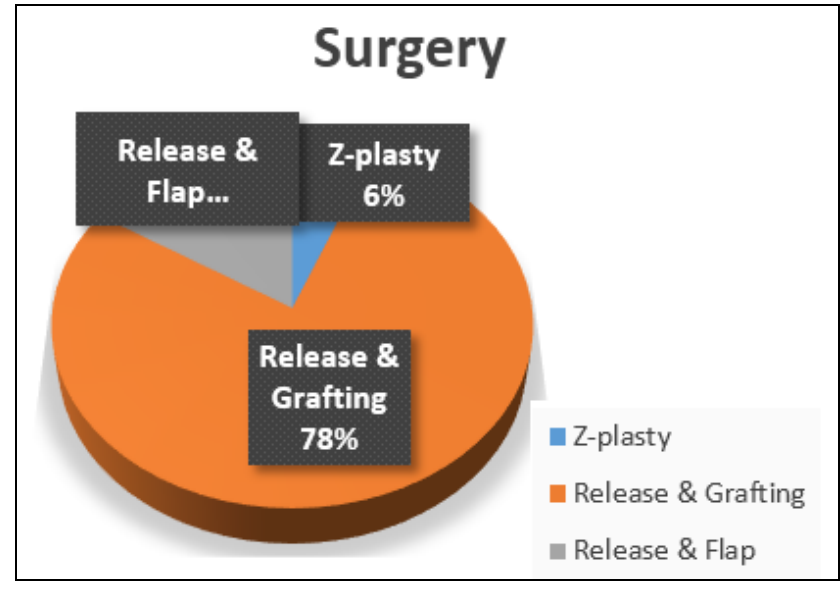

3. Range of Movement Achieved with Surgery

\begin{tabular}{|c|c|c|c|}
\hline ROM Achieved & $\mathbf{7 5 \%}$ or less & $\mathbf{7 6 \%}-\mathbf{9 0} \%$ & $\mathbf{9 1 \% - 1 0 0 \%}$ \\
\hline No. of Patients & 0 & 13 & 37 \\
\hline $\begin{array}{c}\text { Percentage of } \\
\text { Patients }\end{array}$ & $0 \%$ & $26 \%$ & $74 \%$ \\
\hline \multicolumn{4}{|c|}{ Table 4 } \\
\hline
\end{tabular}

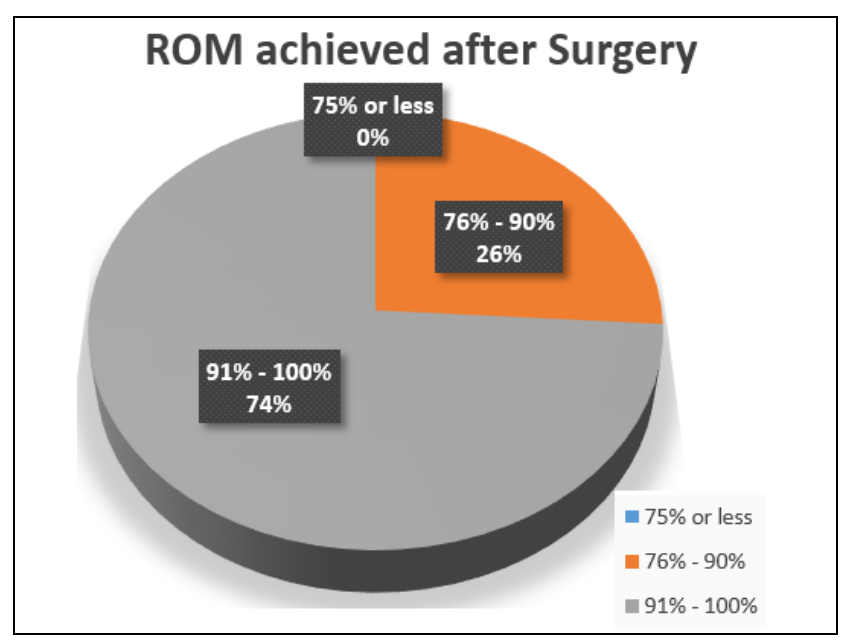

4. Evaluation at Follow Up for Rehabilitation

a) Number of patients who came for follow up

\begin{tabular}{|c|c|c|}
\hline Follow-Up & Yes & No \\
\hline No. of Patients & 40 & 10 \\
\hline $\begin{array}{c}\text { Percentage of } \\
\text { Patients }\end{array}$ & $80 \%$ & $20 \%$ \\
\hline \multicolumn{2}{|c|}{ Table 5 } \\
\hline
\end{tabular}

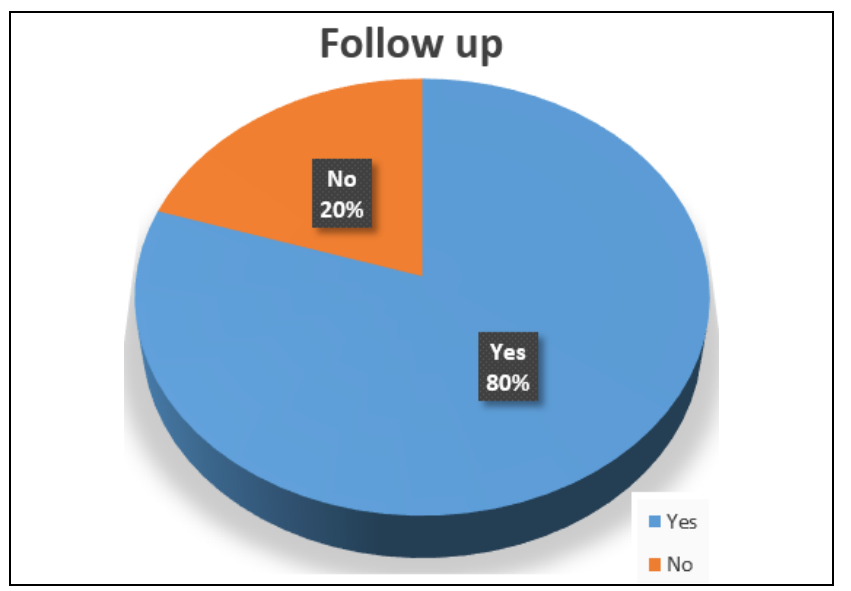

b) Number of patients who used splints at follow up

\begin{tabular}{|c|c|c|}
\hline Splint Used & Yes & No \\
\hline No. of Patients & 30 & 10 \\
\hline $\begin{array}{c}\text { Percentage of } \\
\text { Patients }\end{array}$ & $75 \%$ & $25 \%$ \\
\hline \multicolumn{2}{|c|}{ Table 6 } \\
\hline
\end{tabular}

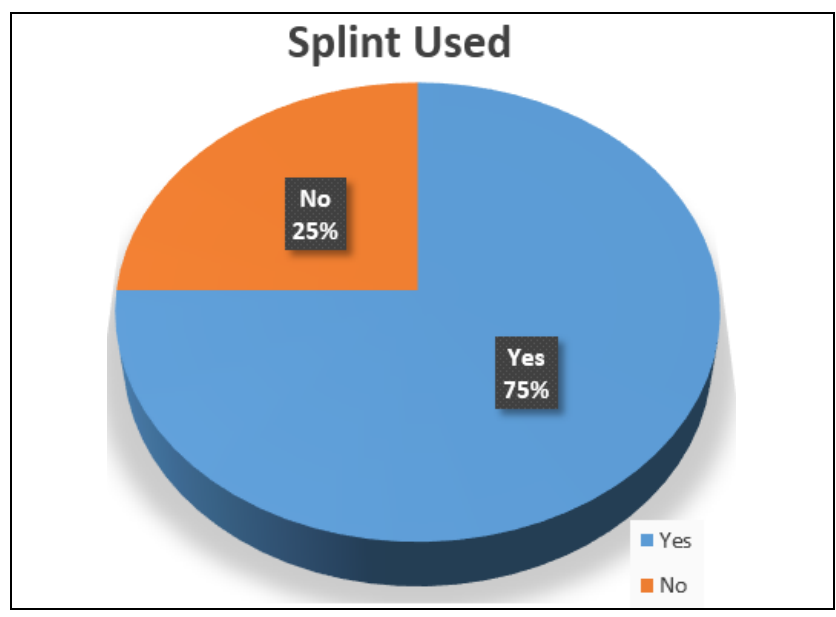

c) Scar assessment score at follow up

\begin{tabular}{|c|c|c|c|c|}
\hline Scar Score & $\mathbf{9}$ or less & $\mathbf{1 0 - 1 3}$ & $\mathbf{1 4 - 1 8}$ & $\begin{array}{c}\text { Loss to } \\
\text { Follow-Up }\end{array}$ \\
\hline No. of Patients & 11 & 26 & 3 & 10 \\
\hline $\begin{array}{c}\text { Percentage of } \\
\text { Patients }\end{array}$ & $22 \%$ & $52 \%$ & $6 \%$ & $20 \%$ \\
\hline \multicolumn{5}{|c|}{ Table 7 } \\
\hline
\end{tabular}

\section{d) Range of movement achieved at follow up}

\begin{tabular}{|c|c|c|c|c|}
\hline $\begin{array}{c}\text { ROM at follow- } \\
\text { Up }\end{array}$ & $\begin{array}{c}\mathbf{7 5 \%} \text { or } \\
\text { Less }\end{array}$ & $\begin{array}{c}\mathbf{7 6 \%} \\
\mathbf{9 0 \%}\end{array}$ & $\begin{array}{c}\mathbf{9 1 \%} \\
\mathbf{1 0 0 \%}\end{array}$ & $\begin{array}{c}\text { Loss to } \\
\text { Follow-Up }\end{array}$ \\
\hline No. of Patients & 19 & 18 & 3 & 10 \\
\hline $\begin{array}{c}\text { Percentage of } \\
\text { Patients }\end{array}$ & $38 \%$ & $36 \%$ & $6 \%$ & $20 \%$ \\
\hline $\begin{array}{c}\text { Patients who used } \\
\text { splints }\end{array}$ & $9(18 \%)$ & $18(36 \%)$ & $3(6 \%)$ & - \\
\hline $\begin{array}{c}\text { Patients Who Did } \\
\text { Not Use Splints }\end{array}$ & $10(20 \%)$ & $0(0 \%)$ & $0(0 \%)$ & - \\
\hline \multicolumn{5}{|c|}{ Table 8 } \\
\hline
\end{tabular}

e) Deficit remaining at follow up

\begin{tabular}{|c|c|c|c|}
\hline Deficit in ROM & $\begin{array}{c}\mathbf{2 5 \%} \text { or } \\
\text { Less }\end{array}$ & $\begin{array}{c}\mathbf{2 6 \%}- \\
\mathbf{5 0 \%}\end{array}$ & $\begin{array}{c}\text { More } \\
\text { Than } \\
\mathbf{5 0 \%}\end{array}$ \\
\hline $\begin{array}{c}\text { In Patients Using Splint } \\
\text { (\% of total no. of patient } \\
\text { using splint) }\end{array}$ & $25(83 \%)$ & $5(17 \%)$ & $0(0 \%)$ \\
\hline $\begin{array}{c}\text { In Patients Not Using Splint } \\
\text { (\% of total no. of patients not } \\
\text { using splint) }\end{array}$ & $0(0 \%)$ & $9(90 \%)$ & $1(10 \%)$ \\
\hline Total Number of Patients & 25 & 14 & 1 \\
\hline \multicolumn{2}{|c|}{ Table 9 } \\
\hline
\end{tabular}




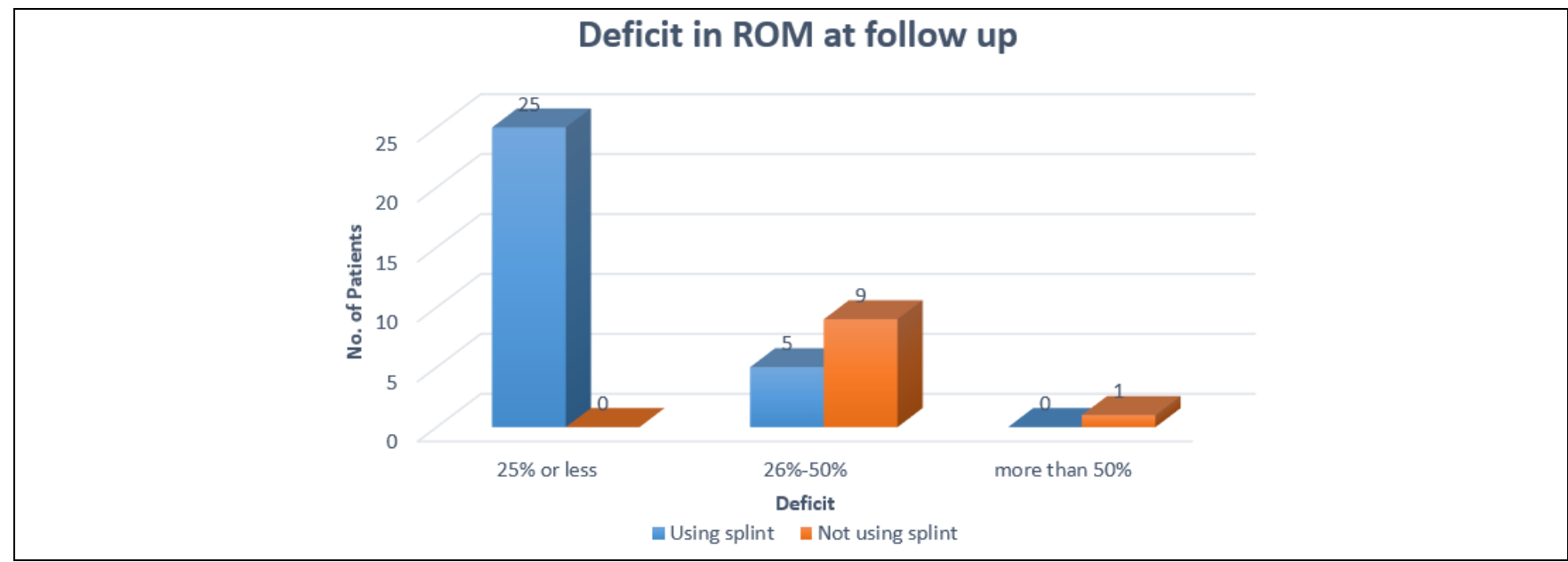

f) Deficit in ROM at pre-op and follow up in patients who received flap versus skin grafting

\begin{tabular}{|l|l|l|l|l|l|l|l|l|l|}
\hline Surgery & $\begin{array}{l}\text { No. of } \\
\text { Patients } \\
\end{array}$ & \multicolumn{9}{|c|}{$\begin{array}{l}\text { Po-op } \\
\text { (excluding } \\
\text { loss at } \\
\text { follow up) }\end{array}$} & $\begin{array}{l}25 \% \\
\text { or } \\
\text { less }\end{array}$ & $\begin{array}{l}26 \%- \\
50 \%\end{array}$ & $\begin{array}{l}51 \%- \\
75 \%\end{array}$ & $\begin{array}{l}\text { More } \\
\text { than } \\
75 \%\end{array}$ & $\begin{array}{l}25 \% \text { or } \\
\text { less }\end{array}$ & $\begin{array}{l}26 \%- \\
50 \%\end{array}$ & $\begin{array}{l}51 \%- \\
75 \%\end{array}$ & $\begin{array}{l}\text { More } \\
\text { than } \\
75 \%\end{array}$ \\
\hline $\begin{array}{l}\text { Flap or } \\
\text { Z-plasty }\end{array}$ & 11 & 0 & $3(27 \%)$ & $3(27 \%)$ & $5(46 \%)$ & $6(55 \%)$ & $5(45 \%)$ & 0 & 0 \\
\hline $\begin{array}{l}\text { Skin } \\
\text { grafting }\end{array}$ & 29 & 0 & $1(3 \%)$ & $11(38 \%)$ & $17(59 \%)$ & $13(45 \%)$ & $15(52 \%)$ & $1(3 \%)$ & 0 \\
\hline
\end{tabular}

g) Scar Score at pre-op and follow up in patients who received flap versus skin grafting

\begin{tabular}{|c|c|c|c|c|c|c|c|}
\hline \multirow[t]{3}{*}{ Surgery } & \multirow{3}{*}{$\begin{array}{l}\text { No. of } \\
\text { Patients } \\
\text { (excluding } \\
\text { loss at } \\
\text { follow up) }\end{array}$} & \multicolumn{6}{|c|}{ Scar score } \\
\hline & & \multicolumn{3}{|c|}{ Pre-op } & \multicolumn{3}{|c|}{ Follow-up } \\
\hline & & $\begin{array}{l}9 \text { or } \\
\text { less }\end{array}$ & $10-13$ & $14-18$ & 9 or less & $10-13$ & $14-18$ \\
\hline $\begin{array}{l}\text { Flap or Z- } \\
\text { plasty }\end{array}$ & 11 & 0 & $6(55 \%)$ & $5(45 \%)$ & $5(46 \%)$ & $4(36 \%)$ & $2(18 \%)$ \\
\hline $\begin{array}{l}\text { Skin } \\
\text { grafting }\end{array}$ & 29 & 0 & $14(48 \%)$ & $15(52 \%)$ & $6(21 \%)$ & $22(76 \%)$ & 0 \\
\hline
\end{tabular}

h) Comparison between pre-op and post-op scar assessment score

\begin{tabular}{|c|c|c|c|c|c|c|c|}
\hline Parameter & Mean & Min & Max & \pm SD & $\begin{array}{c}\text { T } \\
\text { value }\end{array}$ & $\begin{array}{c}\text { P } \\
\text { value }\end{array}$ & Sig/NS \\
\hline Pre-op & 13.75 & 10.00 & 18.00 & 1.89 & 20.45 & 0.000 & HS \\
\hline Post -op & 10.47 & 8.00 & 15.00 & 1.66 & & & \\
\hline
\end{tabular}

i) Comparison between pre-op and post-op deficit in ROM\%

\begin{tabular}{|l|l|l|l|l|l|l|l|}
\hline Parameter & Mean & Min & Max & \pm SD & $\begin{array}{l}\text { T } \\
\text { value }\end{array}$ & $\begin{array}{l}\text { P value } \\
\text { vS }\end{array}$ & $\begin{array}{l}\text { Sig/ } \\
\text { NS }\end{array}$ \\
\cline { 1 - 6 } Pre-op & 75.30 & 34.00 & 100.00 & 17.19 & 15.24 & 0.000 & HS \\
\cline { 1 - 4 } Post -op & 27.27 & 6.00 & 67.00 & 14.04 & & & \\
\hline
\end{tabular}




\section{DISCUSSION}

This study was done in M. Y. Hospital, Indore during the period of January 2016 to March 2017. Following inferences were made from this study. Majority of patients presenting to us were of moderate grade (54\%) or severe grade (46\%) while there was no case of mild contracture. Majority of the patients presented with severe restriction in Range of Motion (ROM) with 54\% presenting with a very severe deficit of more than $75 \%$ of normal ROM, $24 \%$ presented with a severity of $51 \%$ to $75 \%$ deficit while only $12 \%$ presented with deficit less than $50 \%$ of normal ROM. Thus, there is a tendency of patients to seek treatment for scars when it is of moderate to severe grade and causes moderate to severe functional restriction. Majority of patients required Release of contracture with grafting (78\%). Release and flap could be done in $16 \%$ only. While only $6 \%$ could be treated with $\mathrm{Z}$ plasty alone. POP slab was applied in all cases after correction to maintain the limb in corrected position postoperatively and at discharge splint was applied in all patients. In all patients, acceptable level of correction was achieved with $74 \%$ achieving a near normal ROM i.e. 91\%$100 \%$ of normal ROM while rest of the patients $(26 \%)$ achieved $76 \%$ to $90 \%$ of normal ROM. Thus, the treatment offered in this hospital was able to achieve good correction in all cases irrespective of the severity they presented with. Although all patients were counselled properly and advised to come for follow up for reassessment of scar and functional restriction $20 \%$ of patients did not come for the same while $80 \%$ came for regular follow up. Out of 40 patients who did come for follow up $75 \%$ used splints regularly while $25 \%$ showed poor compliance and did not use splint as advised. Thus, compliance with the rehabilitation protocol is problematic in a fraction of patients. At the end of six month follow up period, $22 \%$ patients had a scar assessment score of 9 or less while none came in this group preoperatively. Patients with scar score 10 to 13 were $52 \%$ at follow up as compared to $54 \%$ preoperatively, while only $6 \%$ fell in group 14-18 as opposed to $46 \%$ preoperatively. $20 \%$ patients did not come for follow-up. At the end of six month follow up period, only $6 \%$ patients of the total 50 were found to have ROM between $91 \%$ to $100 \%$ ROM as compared to $74 \%$ patients achieving this in postoperative period. Out of this $6 \%$ all patients were the ones who used splint. $36 \%$ patients had ROM between $76 \%$ to $90 \%$ as compared to $26 \%$ patients falling in this category post operatively. Out of the $36 \%$ all were the ones who used splints. While all patients had ROM above 50\% postoperatively, $38 \%$ patients entered this category at follow up with $18 \%$ using splints and $20 \%$ not using splint. Notably, all the 10 patients who did not use splint fell in this category. At the end of follow-up, of all the patients using splints $83 \%$ of the patients had a deficit less than $25 \%$ of ROM and the rest had $26 \%$ to $50 \%$ deficit. None had more than $50 \%$ deficit. Out of the patients who did not use splint $90 \%$ had deficit $26 \%$ to $50 \%$ of normal ROM and rest had more than $50 \%$ deficit. Notably, none of these patients could maintain a deficit less than $25 \%$. Thus, it was found that although a good level of correction was achieved at the end of follow up, the level of correction was not the same as that achieved postoperatively. This is mainly due to difference in compliance with the rehabilitation protocol explained to the patients. Those who used splints maintained a better level of correction and deficit increased marginally at follow up while those who did not use splints had an increase in deficit at follow up. Notably, 100\% correction could not be achieved at follow up despite best of compliance. This is because of the normal tendency of wound to contract as a part of normal healing process. Thus, we conclude that although the level of correction achieved at follow up cannot be maintained same as the postoperative level but compliance with the rehabilitation protocol prevents the deficit to increase to a great extent.

\section{CONCLUSION}

1. Majority of the patients tend to present for treatment when the scar is of greater severity and causes moderate to severe functional restriction.

2. Most patients required release of contracture followed by split thickness skin grafting while using flap or z-plasty was possible in only some patients.

3. A good level of improvement in functionality was achieved by surgery in all cases irrespective of their severity at presentation.

4. Although most patients came for follow-up and were compliant with the rehabilitation protocol, their compliance needs to be re-evaluated at every follow up and they should be encouraged to follow the advice strictly. Also, they must be counselled that contracture may not be corrected to the full extent despite best of treatment and compliance with rehabilitation protocol, but a good level of improvement can be achieved.

5. Despite good surgical correction, contractures tend to recur after some time, although it can be delayed, and severity reduced by use of splints.

\section{REFERENCES}

[1] www.who.int/mediacentre/factsheets/fs365/en/

[2] Van Baar ME, Essink-Bot ML, Oen IM, et al. Functional outcome after burns: a review. Burns 2006;32(1):1-9.

[3] Brown BC, McKenna SP, Siddhi K, et al. The hidden cost of skin scars: quality of life after skin scarring. J Plast Reconstr Aesthet Surg 2008;61(9):1049-58.

[4] Jordan RB, Daher J, Wasil K. Splints and scar management for acute and reconstructive burn care. Clin Plast Surg 2000;27(1):71-85.

[5] Semer NB, Watts HG. The HELP Guide to Basics of Wound Care.

[6] Gulati S, Joshi BB, Milner SM. Use of Joshi external stabilizing system in postburn contractures of the hand and wrist: A 20-year experience. J Burn Care Rehabil 2004;25(5):416-20.

[7] Procter F. Rehabilitation of the burn patient. Indian J Plast Surg 2010;(Suppl 43):S101-S13. 